\title{
Measurement of The Flow Velocity for Tsunami Wave Propagation
}

\author{
Min $\mathrm{ROH}^{1}$, Mohammad Bagus ADITYAWAN² and Hitoshi TANAKA ${ }^{3}$ \\ ${ }^{1}$ Student Member of JSCE, M. of Eng., Dept. of Civil Eng., Tohoku University \\ (6-6-06, Aramaki, Aoba-ku, Sendai 980-8579, Japan) \\ E-mail:rohmin@kasen.civil.tohoku.ac.jp \\ ${ }^{2}$ Member of JSCE, Dr. of Eng., Dept. of Civil Eng., Tohoku University \\ (6-6-06, Aramaki, Aoba-ku, Sendai 980-8579, Japan) \\ E-mail:bagus@kasen1.civil.tohoku.ac.jp \\ ${ }^{3}$ Fellow Member of JSCE, Professor, Dept. of Civil Eng., Tohoku University \\ (6-6-06, Aramaki, Aoba-ku, Sendai 980-8579, Japan) \\ E-mail:tanaka@tsunami2.civil.tohoku.ac.jp
}

\begin{abstract}
The flow velocity of tsunami wave was estimated by using Particle Image Velocimetry(PIV) and Particle Tracking Velocimetry(PTV). These methods have many advantages that can be used to measure velocity under limited data such as the 2011 off the Pacific Coast of Tohoku Tsunami. The results of video image analysis are evaluated by comparing with theoritical approach. The collected video image is stabilized and rectified in the pre-processing to enhance the accuracy of PIV method, whereas the proposed theoretical method is based on conservation equation. It is found that the estimated flow velocity range is consistent regardless of the method. The method is expected to perform well for analyzing videos and providing information in tsunami cases where there is no adequate measurement data.
\end{abstract}

Key Words : Particle Image Velocimetry(PIV), Particle Tracking Velocimetry(PTV), The 2011 off the Pacific Coast of Tohoku Tsunami, tsunami propagation into a river, flow velocity

\section{INTRODUCTION}

The 2011 off the Pacific Coast of Tohoku Earthquake generated huge tsunami waves. Tsunami wave caused severe damages to the eastern coastal area in Tohoku District. Houses, buildings, and infrastructures were destroyed, as well as hydraulic measurement stations in coastal areas and rivers. Thus, data availability is limited. On the other hand, these data are crucial in the recoveries as well as future disaster prevention in coastal area, estuary and rivers.

There were several videos, recorded at the damaged areas due to the 2011 tsunami event. These videos may provide various information regarding physical parameters of tsunami wave. The flow velocity is considered as an important physical parameter for understanding the mechanism of tsunami propagation. In general, PIV method is widely used to measure the flow velocity from recorded video images. The method is widely used in various engineering fields. Furthermore, measurement devices and technics have been developed to further enhance
PIV. It is expected that the method will perform well in practical application.

PIV measurement technics have been studied in various flow condition such as swash flow, river flood flow and so on ${ }^{1,2)}$. The flow velocity was estimated by laboratory experiments and using PIV method based on image analysis, and to improve its availability for real field ${ }^{3), 4}$. Recently, the video image recording of the last tsunami event was analized and compared with past tsunami event on the island of Hokkaido ${ }^{5}$. However, it required expensive measurement devices and large scale laboratory experiment. Moreover, the images were obtained from the fixed camera angle like CCTV. Nevertheless, PIV analysis can be applied to the collected image. PIV analysis was used to assess the characteristics of The Great Indian Tsunami 2004 in Banda Aceh from survivor videos ${ }^{6}$. Unfortunately, it was not verified due to the lack of tsunami data and information. Therefore, verification of PIV is crucial to allow this method for further application in assessing tsunami characteristic based on collected videos of a tsunami event. 
In this study, PIV method is used and verified by comparing the estimated velocity with theoretical approach, and tracking debris method. The methods are applied in the case of tsunami propagation due to the 2011 off the Pacific Coast of Tohoku Earthquake.

\section{STUDY AREA}

Study area is the Sunaoshi River in Miyagi Prefecture as shown in Fig.1. This area is chosen based on the data availability in order to verify PIV method for assessing the flow velocity in a real case tsunami. It was severely damaged during the 2011 off the Pacific Coast of Tohoku Earthquake. Nevertheless, the Sunaoshi River has sufficient data for this study, i.e. water level data and videos.

The collected video was recorded by a digital personal camera at $3.3 \mathrm{~km}$ from the river mouth. Water level data was obtained from five measurement stations. The location of the video recording and the water level measurement stations are shown in Fig.2.

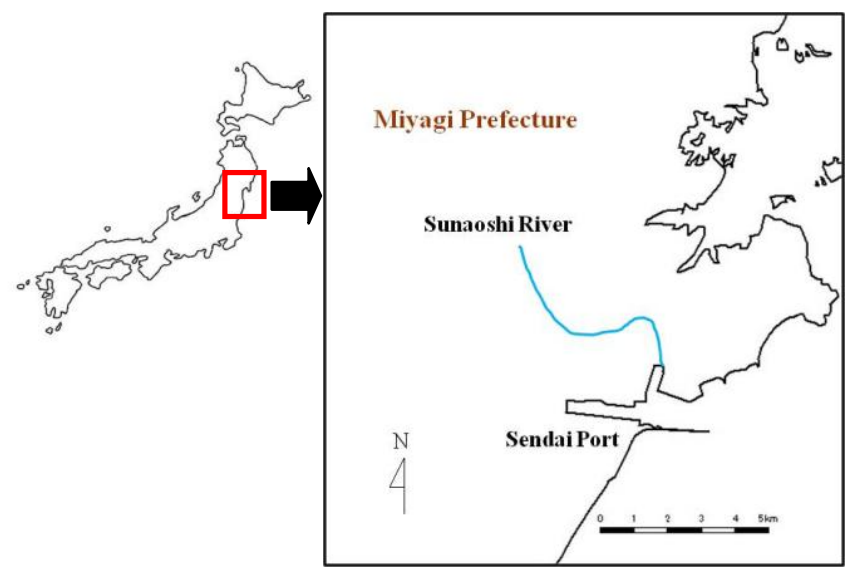

Fig.1 Location of study area

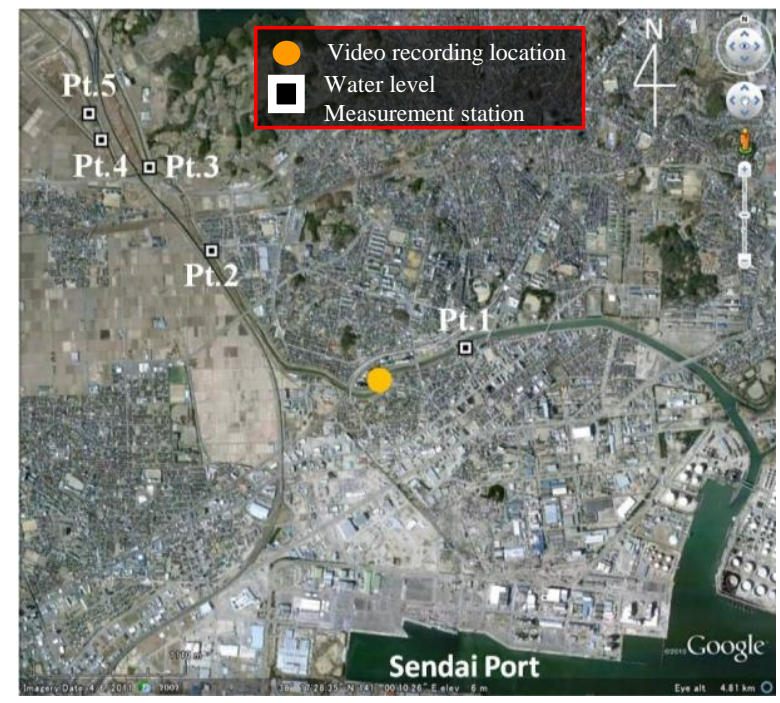

Fig.2 Location of video recording and water level measurement stations

\section{METHODOLOGY}

\section{(1) Pre-processing for image analysis}

Pre-processing covering image stabilization and image rectification is crucial in video image analysis. These processes correct errors that may arrise due to the camera movement and camera viewpoint.

The raw video data should be stabilized because it may have distortion due to oblique view and camera motion during the recording process. In this process, several fixed points such as building, structures were used to make a stable video frame. Thus, each video frame will be analyzed and adjusted to ensure that the stable video frame remains in constant position. A stable video may be recorded using fix axis such as tripod or other means. However, video recordings from amateur or news are mostly recorded by hands such as the video used in this study. Therefore, this process is crucial for analyzing video images. The level of stabilization has significant effect to the overall accuracy of the video image analysis. Four fixed points were chosen and used in this study as shown in Fig.3 (a).

The stabilized video does not contain any information of coordinate system. Therefore, image rectification in pre-processing is required to give local coordinate system to the video image. The process plays an important role in determining the accurate distance which is crucial for analyzing flow velocity and direction from images. The rectification results for the selected red dot area in Fig.3 (a) is shown in Fig.3 (b).

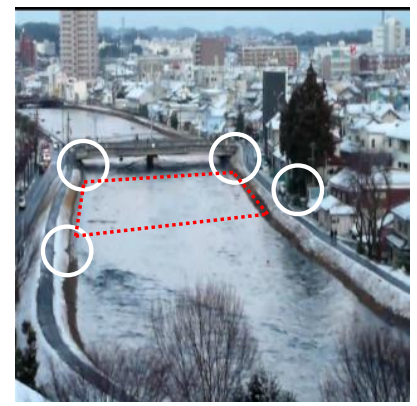

(a) Fixed-points and target area

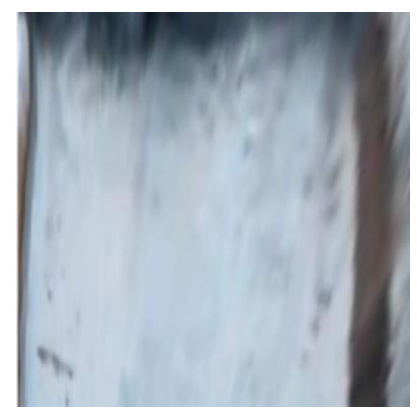

(b) Rectified image of target area
Fig.3 Pre-processing for PIV method

\section{(2) Velocity assessment by PIV and PTV}

The pre-processed video images were analyzed by PIV method and tracking debris method. Recently, various techniques are being developed to obtain stable and exact result in this field. Also, advanced analysis method have been tried to estimate the characteristics of flow behaviors. Performance and capabilities of various PIV analysis were summarized and given in the reference ${ }^{7}$. 
In this study, PIV method based on the background of Large-Scale Particle Image Velocimetry(LSPIV) is used to trace the difference of luminance for a period of time. Tracking debris method focuses on the object in the video image. It was assumed that the debris was regarded as one particle on water surface. The method concept is based on Particle Tracking Velocimetry(PTV).

First of all, two areas in the video were selected. They are location A (river downstream) and location B (river upstream) as shown in Fig.4. Therefore, flow velocity changes along the river can be observed. Moreover, PTV method was applied to location B.

Furthermore, the theoretical approach based on conservation equation is applied to the measured water level data for evaluating the flow velocity variation due to tsunami propagation in this river.

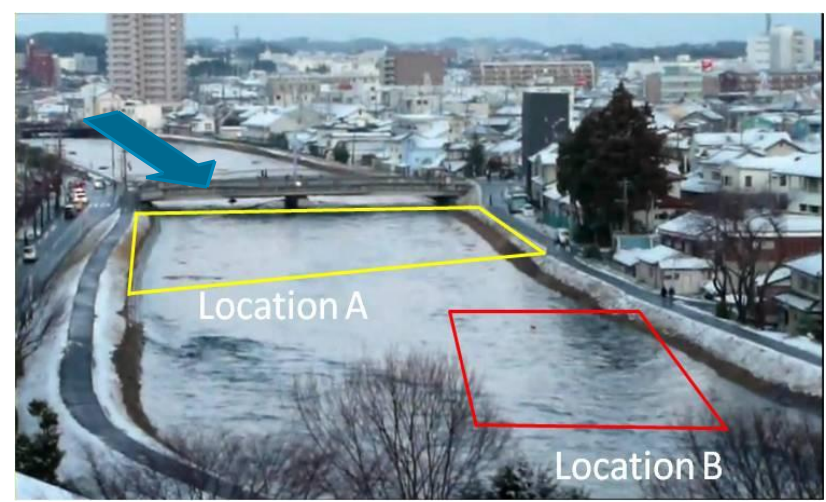

Fig.4 Locations for image analysis

(Sunaoshi River)

\section{RESULTS}

The tsunami flow velocity were estimated using three different methods in this study. They are the PIV method, PTV method, and the theoritical approach. The results from these methods were compared.

\section{(1) Velocity estimation using PIV}

The tsunami flow velocity can be determined by the time interval and displacements. The mean velocity at a specific zone was calculated by averaging vector fields over a $1 \mathrm{sec}$ time interval. PIV method was utilized to Location A and Location B that are composed of 225 and 100 estimation points, respectively.

Fig.5 shows the averaging flow velocity vectors during $1 \mathrm{sec}$ in Location A. The standard deviation was used to measure the error during a $1 \mathrm{sec}$ interval in the estimation field. According to the time, the mean tsunami flow velocity including the standard deviation value is shown in Fig.6. The calculated mean velocity and standard deviation value of Location A mean that various flow patterns were obtained throughout Location A by the difference of range between mean velocity and standard deviation value.
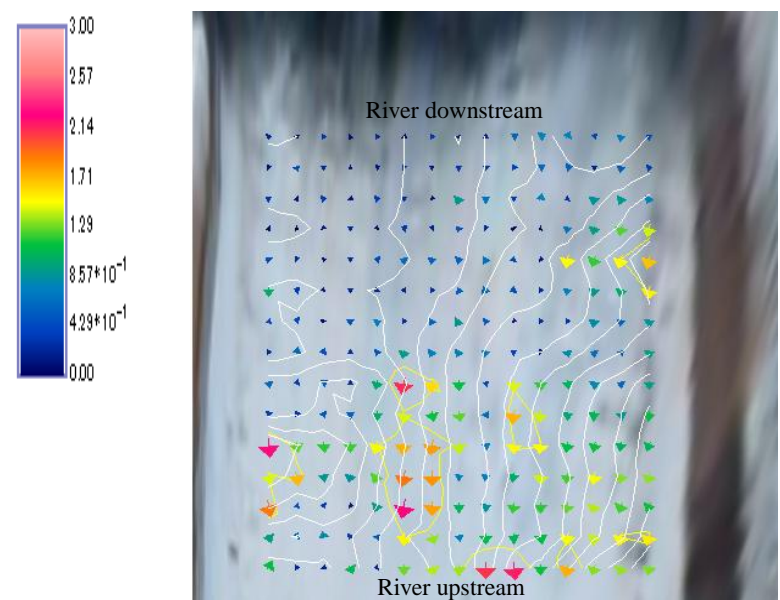

Fig.5 Velocity vectors at 16:03:42 (Location A)

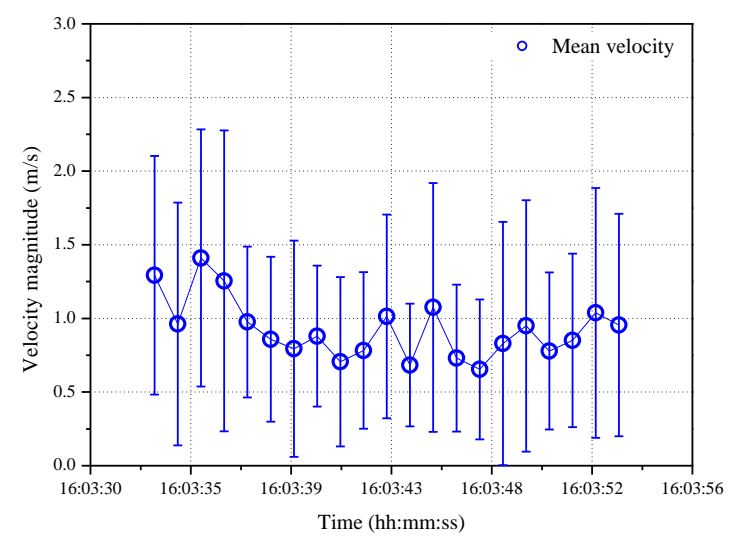

Fig.6 Mean and standard deviation of velocity (Location A)

As seen in Fig.7 (a), (b) and (c), the change of velocity vectors in Location $B$ is shown according to the time. White line is streamline, and contour line is velocity magnitude during $1 \mathrm{sec}$ time interval. There is shown the velocity vectors at three different time because Location B provides the point of comparison between different methods as well as the effect of river topography. The effect can be confirmed by streamlines that is shown along the curvature of river channel from river downstream to river upstream.

In Fig.8, mean velocity and standard deviation value of Location B provide that smaller target area of measurement lead to reliable result compared with Location A. However, tsunami wave fluctuates every 
time in a real field as well as the flow velocity is changed according to the place and time. It can be obtained spurious vectors that wrong direction vectors or extremely high velocities may be released due to distorted video images in pre-processing stage. It is that the accuracy of analysis method is rely on the stabilization and rectification process. From the measurement result, the pre-processing step for image analysis in this paper is able to overcome the conventional problems of PIV method.
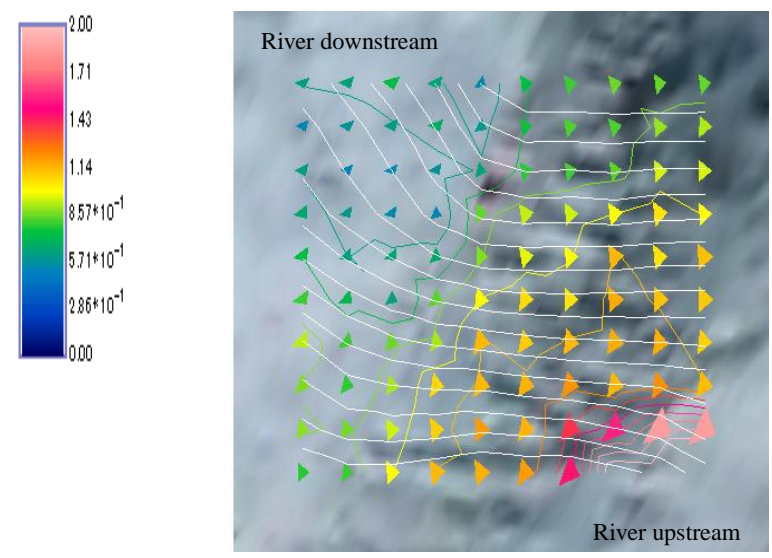

(a) 16:03:42
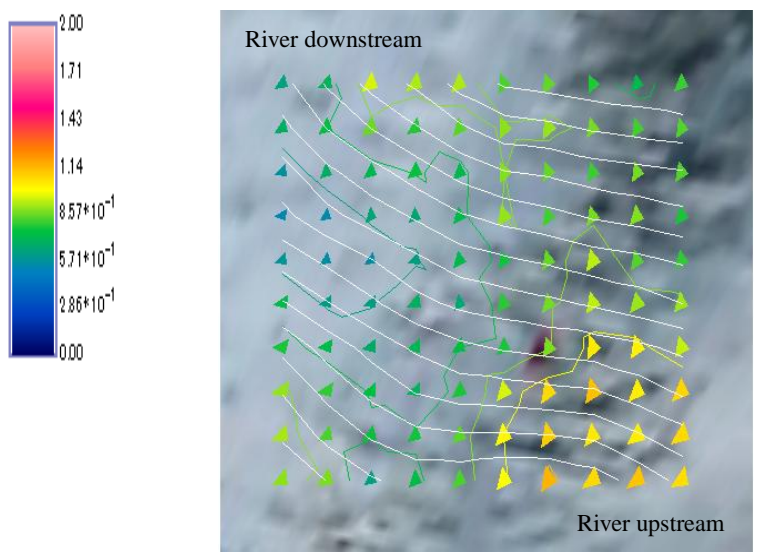

(b) 16:03:49
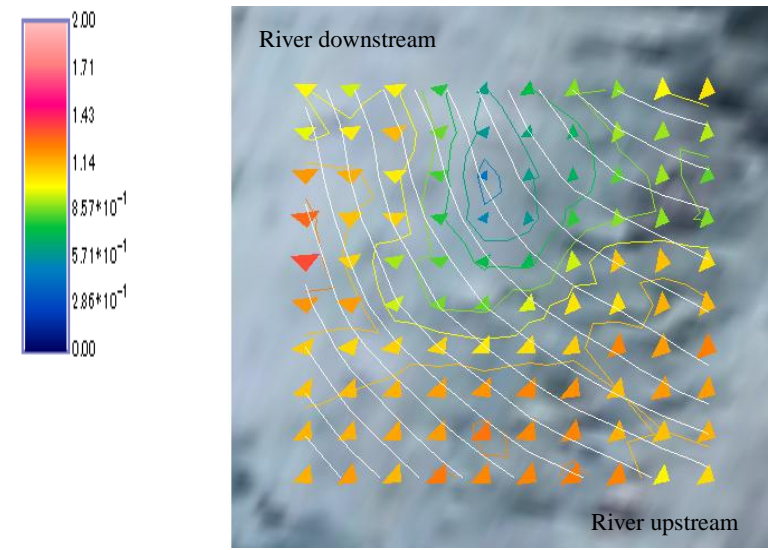

(c) 16:03:55

Fig.7 Velocity vector (Location B)

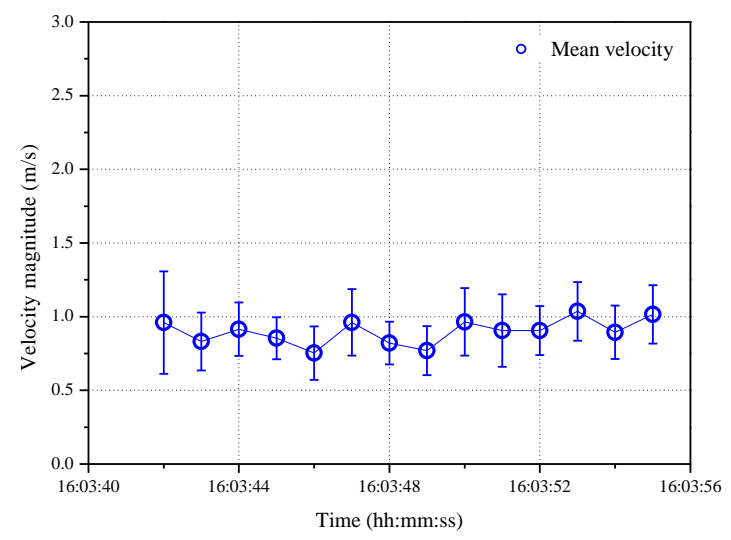

Fig.8 Mean and standard deviation of velocity (Location B)

\section{(2) Velocity estimation using PTV}

Tracking debris method was applied to Location B. The red object can be found floating in the raw video as shown in Fig.9. Thus, the displacement of this object can be detected. This object is chosen as the target for PTV analysis.
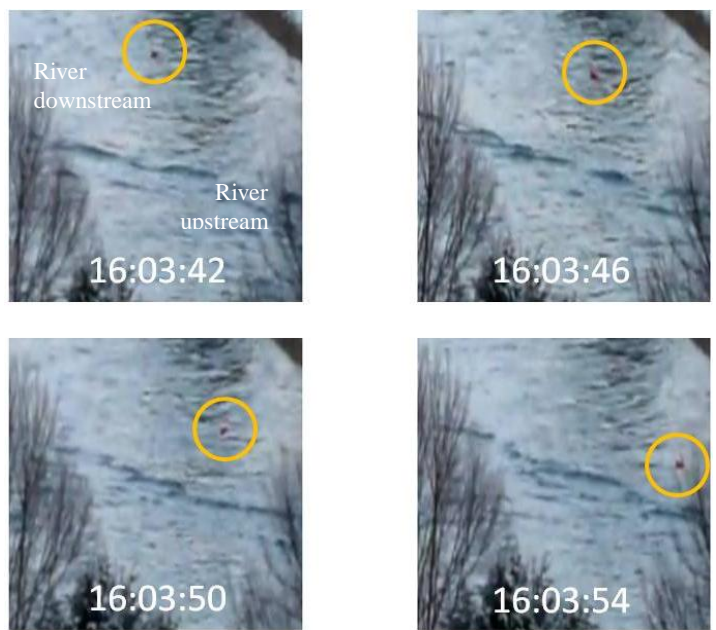

Fig.9 Movement of tsunami debris(Location B)

The velocity magnitude and vector of debris are shown in Fig.10 (a) and (b) respectively. The flow velocity of debris was steadily increasing during around 15 seconds, and then the peak velocity is attained as $1.03 \mathrm{~m} / \mathrm{s}$. The direction of debris can be confirmed by vector analysis.

\section{(3) Velocity estimation using a conservation equation}

The calculation method is based on the conservation equation ${ }^{8)}$. The flow velocity in the river will be calculated using Eq.(1a).

$$
\frac{\partial A}{\partial t}+\frac{\partial Q}{\partial x}=0
$$

where, $A$ is river cross-section area, $Q$ is river discharge, $t$ is time, and $x$ is an arbitrary point along river upstream direction. 


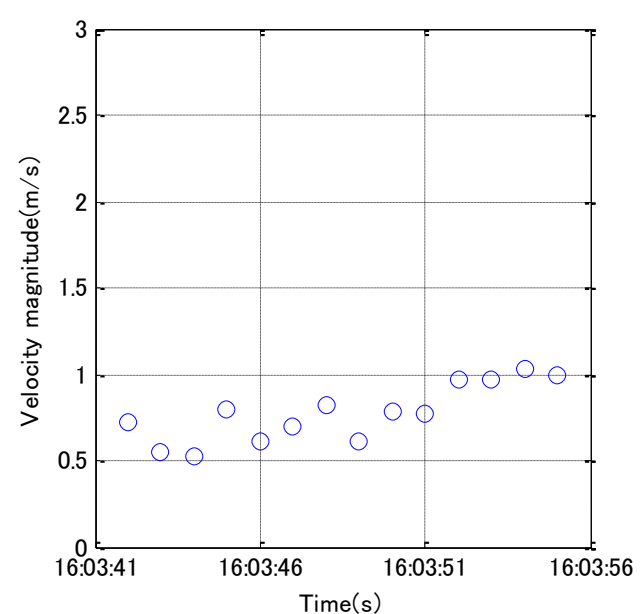

(a) Velocity magnitude

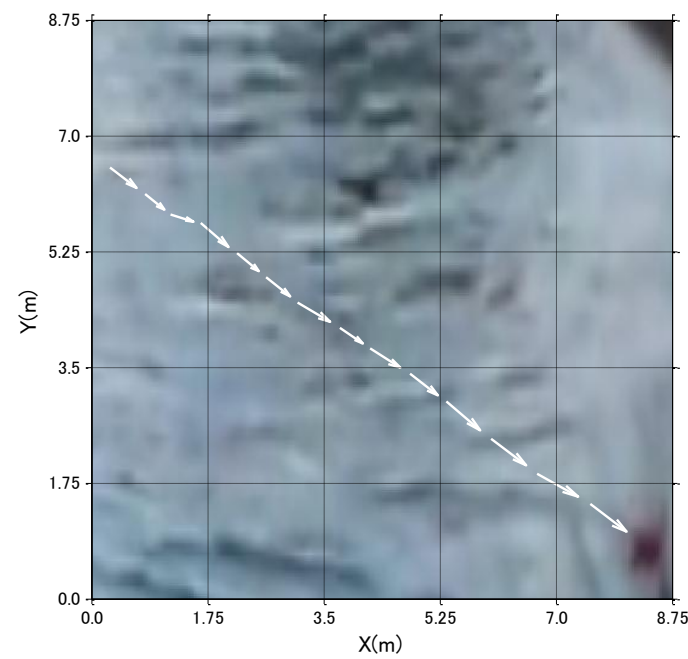

(b) Vector components

Fig.10 Velocity measurement of tsunami debris

This equation can be rewritten as,

$$
\int_{x_{1}}^{x_{2}} B \frac{\partial \eta}{\partial t} d x+Q_{2}=Q_{1}
$$

where $B$ is river width, $\eta$ is water level, $Q_{1}$ and $Q_{2}$ are discharge at $x_{1}$ and $x_{2}$, respectively. If water level variation is given due to tsunami wave propagation into river, tsunami flow velocity can be estimated using Eq.(1b).

It was assumed that the river cross section is rectangular and water surface motion due to tsunami wave between measurement stations moved linearly at the same time. In addition, end of river upstream discharge is ignored. The reasons are that the season was dry season when the earthquake occurred, and the selected river is commonly classified as second class river. Thus, the upstream end boundary is zero.

The calculation result of river discharge $(Q)$ and flow velocity $(V)$ in Sunaoshi River are depicted in Fig.11 and Fig.12 respectively. From these figures, the positive value means flow direction from river downstream to river upstream. It can be observed that the peak velocity becomes slower in the function of distance from the river mouth. These figures also informs how far the effect of tsunami wave propagation into Sunaoshi River.

It was found that the maximum river discharge and flow velocity attained to $150 \mathrm{~m}^{3} / \mathrm{s}$ and $1.4 \mathrm{~m} / \mathrm{s}$ at the measurement station of $2.9 \mathrm{~km}$ from river mouth. The calculation result of conservation equation depends on the measurement time interval, river topographical characterastics and the distance which is between two water level measurement stations.

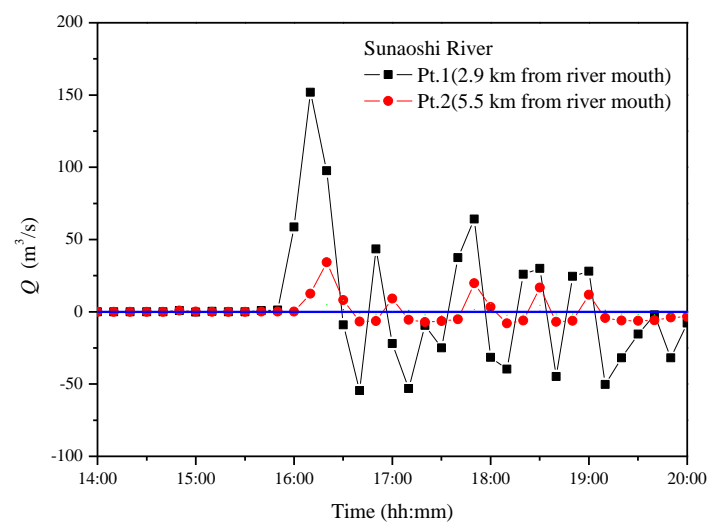

Fig.11 Calculated river discharge ${ }^{8)}$

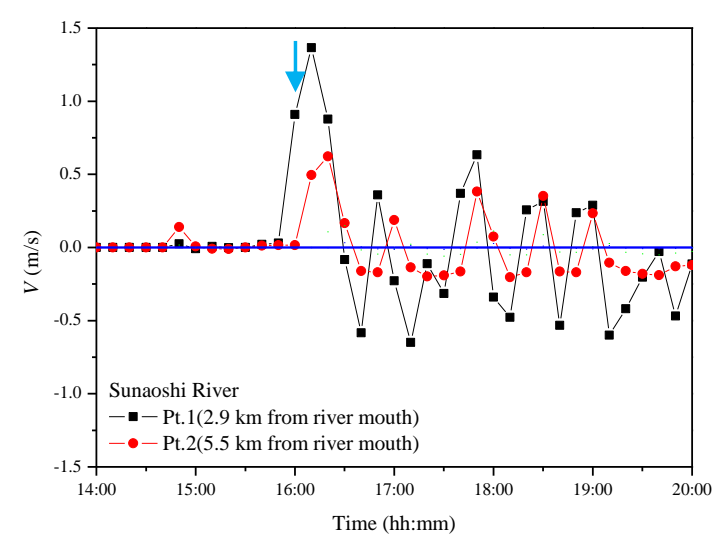

Fig.12 Calculated tsunami flow velocity ${ }^{8)}$

\section{(4) Comparison results}

To verify the methods, the calculation and image analysis results were reploted in Fig.13 according to the real time. The flow velocity of tsunami was estimated to be ranging from $0.6 \mathrm{~m} / \mathrm{s}$ to $1.0 \mathrm{~m} / \mathrm{s}$ by PIV and tracking debris method. Meanwhile, the calculated flow velocity were attained to the range of 1.0 $\mathrm{m} / \mathrm{s}$ to $1.2 \mathrm{~m} / \mathrm{s}$ by conservation equation at the blue arrow in Fig.12. It was found that the measured flow velocity from PIV and tracking debris analysis is closer to the calculated flow velocity by using conservation equation at Point $1(2.9 \mathrm{~km}$ from the river mouth) than Point 2 (5.5 km from the river mouth). 


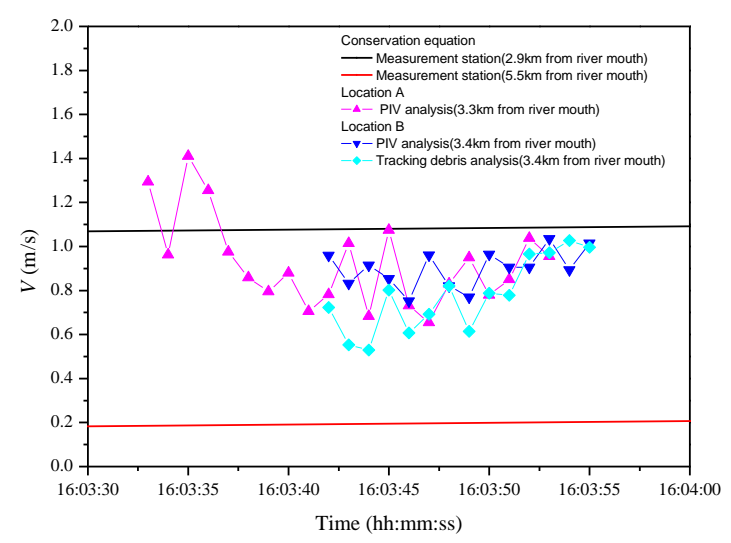

Fig.13 Comparison calculation result and image analysis result

The results are dependable and consistent between PIV analysis, PTV analysis and conservation equation results although the comparison anlysis was limited. The result of conservation equation was obtained from 10 minutes time interval data. On the other hand, video image analyses were conducted for a very short period of time ( 25 seconds). Nevertheless, it seems not only to have the similar tendency of flow velocity variation but also these methods are able to estimate the flow velocity from the distorded video images including moving camera motion and oblique viewpoint.

\section{CONCLUSIONS}

PIV method was applied to analyze flow velocity at Sunaoshi River due to tsunami in 2011. The application of PIV method has been verified by various approaches in this paper. The PIV results were compared to the results from PTV and theoretical approach.

Overall, the results from all of the methods suggested similar trend and behavior. Thus, this measurement process and analysis method can be proposed to overcome the conventional limitations such as moving camera motion and oblique viewpoint. Therefore, the accuracy of the results can be improved regardless of the video source.

In conclusion, the presented methods can be useful to achieve the estimation of tsunami flow velocity, especially in the area where there are no adequate measurement data. Furthermore, image analysis methods (PIV and PTV) can be applied to assess tsunami characteristic in other regions based on various video sources. It is hoped that more detail analyses based on the presented methods in this study may provide a better understanding of the mechanism of the tsunami propagation.

ACKNOWLEDGMENT: The authors would like to thank the financial supports from the Grant-in-Aid for Scientific Research from JSPS (No. 21360230, No. 22360193, No. 2301367), Grant-in-Aid for Scientific Research from the River Environmental Fund (REF) in charge of the Foundation of River and Watershed Environmental Management (FOREM), as well as Assistance for Technological Development, Tohoku Construction Association. The second author is a Postdoctoral Fellow granted by JSPS (No. P11367).

\section{REFERENCES}

1) Fujita, I. and Kawamura, Y. : Discharge measurements of flood flow by imaging technology and float method, XXIX IAHR Congress Proceedings, 2001.

2) Holland, K. T., Puleo, J. A. and Kooney, T. N. : Quantification of swash flows using video-based particle image velocimetry, Coastal Engineering, No. 44, pp. 65-77, 2001.

3) Hauet, A., Creutin, J. D. and Belleudy P. : Sensitivity study of large-scale particle image velocimetry measurement of river discharge using numerical simulation, J. of Hydrology, No. 349, pp. 178-190, 2008.

4) Kantoush, S. A., Schleiss, A. J., Sumi, T. and Murasaki, M. : LSPIV implementation for environmental flow in various laboratory and field cases, $J$. of Hydro-environment Research, No. 5, pp. 263-276, 2011.

5) Matsukawa, Y., Ara, S., Kato, M., Aburakawa, Y., Watanabe, K., Nagaoka, H. and Yamaguchi, H. : Observation of the tsunami runup in the Hokkaido Tokachi River due to the 2011 Off The Pacific Coast of Tohoku Earthquake, J. of Japan Society of Civil Engineerings, Ser.B1 (Hydraulic Engineering), Vol. 68, No.4, pp. 1513-1518, 2012.(in Japanese)

6) Frizt, H. M., Borrero, J. C., Synolakis, C. E. and Yoo, J. : 2004 Indian Ocean tsunami flow velocity measurements from survivor videos, Geophysical Research Letters, Vol. 33, L24605, 2006.

7) Muste, M., Fujita, I. and Hauet, A. : Large-scale particle image velocimetry for measurements in riverine environments, Water Resources Research, Vol. 44, W00D19, 2008.

8) Roh, M., Tanaka, H., Adityawan, M. B., Mano, A. and Udo, $\mathrm{K}$. : Study on tsunami celerity and velocity ascending rivers, J. of Japan Society of Civil Engineerings, Ser.B1 (Hydraulic Engineering), Vol. 68, No.4, pp. 253-258, 2012.(in Japanese) 